\title{
Ein unbekanntes Bildnis Franz Anton Mesmers
}

\author{
Von Dr. Helmut Eckert, Offenbach am Main
}

Vom einstmals weitberühmten Entdecker des «tierischen Magnetismus», Franz Anton Mesmer, sind bisher, von mehr oder weniger unbedeutenden Stichen abgesehen, nur zwei Bildnisse bekannt: das Ölbild im Kernerhaus in Weinsberg, das aus Mesmers Nachlaß stammt und vom Freiherrn von Laßberg 1815 in Meersburg erworben und später an Justinus Kerner geschenkt worden war, und das vor einigen Jahren als Porträt Mesmers erkannte, sehr ansprechende Pastellbild im Besitz des Rittersaalvereins in Burgdorf (Schweiz) ${ }^{1}$. Dieses Bild dürfte, nach der Eleganz der Erscheinung beurteilt, aus der Glanzzeit Mesmers unter dem ancien régime stammen.

Jetzt ist ein drittes Bildnis aufgetaucht, eine Miniatur, die hier zum erstenmal veröffentlicht wird. Sie stammt ebenfalls aus Mesmers Besitz. Die Wiederentdeckung geschah unter reizvollen Umständen.

Der Münchner Arzt Dr. Wilhelm Wurm, ein Anhänger des Mesmerismus, weilte 1856 in Meersburg und schrieb in sein Tagebuch: «Ich besuchte, nicht ohne tiefe Rührung, die Ruhestätte dieses ganz besonderen Mannes. Ich gedachte des Todten großer fortlebender Entdeckung, seines uneigennützig dem Wohle der Menschheit gewidmeten Lebens und des geernteten Undanks ... Noch will ich erwähnen, daß ich so glücklich war, während meines Aufenthaltes Mesmers Miniaturporträt, welches er selbst noch in Besitz gehabt, von Herrn Kaufmann Vogel an mich zu bringen.»

Der Schreiber dieser Zeilen kannte noch die Tochter jenes Kaufmanns Vogel aus Meersburg und erhielt einst von ihr einen silbernen Löffel Mesmers mit dessen Monogramm. Sie erwähnte dabei, daß ihre Großmutter Verschiedenes, u. a. Silber, aus Mesmers Nachlaß erworben habe. Von der Miniatur wußte sie anscheinend nichts. Erklärlich, da sie 1856 - als W URM das Bild erwarb - erst acht Jahre alt war.

Vor einiger Zeit besuchte ich Herrn Staatsarchivar Dr. Johannes Schultze in Berlin-Dahlem zu einem Gedankenaustausch über geheime Gesellschaften des 18. Jahrhunderts. Niemand erwähnte Mesmer, obwohl er solchen geheimen Verbindungen zweifellos angehört hat. Nur «zufällig» galt beim Abschied meine Frage einem Miniaturbildnis, das ziemlich entfernt hing. Es sei Mesmer.

1 Vgl. Alfred G. Roth, Ein neues Bild Franz Anton Mesmers, in Gesnerus 6 (1949) 45. 


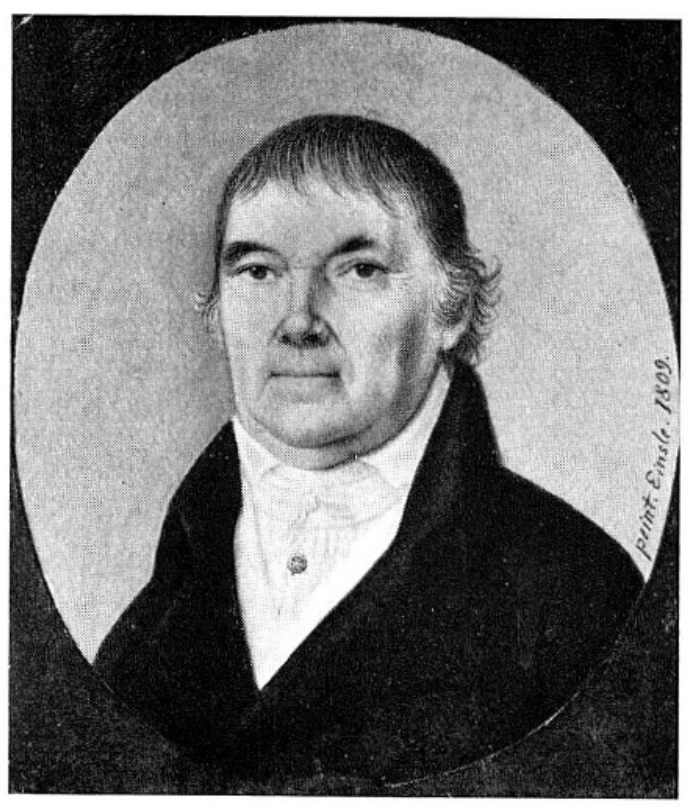

Franz Anton Mesmer

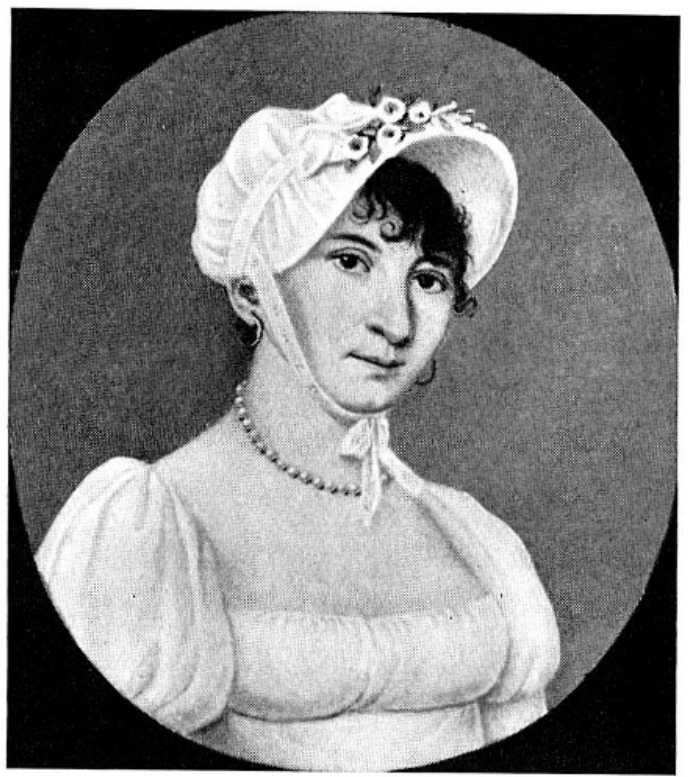

Anna Maria Seeger geb. Holderrieth 
Wer das Porträt in Weinsberg gesehen hat, erkennt ihn gleich. Es war aber jene verschollene Miniatur aus Mesmers Besitz, die Wurm 1856 gekauft hatte. Von WURM unterschrieben und datiert, stand auf der Rückseite der Vermerk, daß er das Bild vom Kaufmann Vogel in Meersburg erworben, an den es aus Mesmers Nachlaß gekommen sei. Dr. Schultze hat es vor Jahren aus einem Berliner Nachlaß übernommen ${ }^{2}$.

Vielleicht aus Anlaß seines 75. Geburtstags hat sich hier Mesmer malen lassen, denn die Miniatur ist "peint. Einsle. 1809» signiert. Der Künstler kann nur Josef Einste sein. Von ihm sind mehrere Miniaturen in dieser Manier bekannt geworden. Nach Thieme-Becker, Allgemeines Lexikon der bildenden Künstler, Band X (1914), war EINsLE 1794 in Göggingen geboren, ein Miniaturmaler, der sich an verschiedenen Orten aufhielt - anscheinend reisend tätig war - und «nach 1850 » in Augsburg starb. Wenn wir nicht

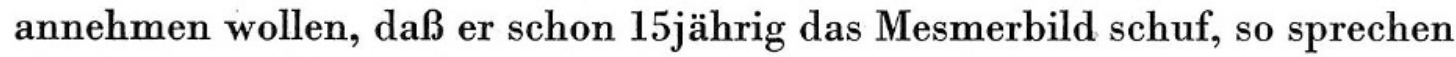
die dürftigen Nachrichten über sein Leben und Arbeiten dafür, daß auch das Geburtsdatum unsicher sein könnte. Die geistige und körperliche Frische, die Einsles Mesmerbildnis widerspiegelt, wird durch schriftliche Zeugnisse von der Vitalität des 75 jährigen bestätigt. Die Miniatur entstand in Frauenfeld, wo Mesmer von 1807 bis 1812 als Schweizer Bürger lebte. Schon 1794 - nach seiner politischen Verfolgung in Wien - hatte er das «thurgauische Landrecht» erworben. Von Frauenfeld aber nahm auch die zweite Periode der Popularität Mesmers ihren Ausgang. Seit jener Mode des Mesmerismus in Frankreich während der letzten Jahre des Königtums war Mesmer nahezu verschollen. Erst als ihn 1808 der Arzt Dr. ZugenbüHLer aus Glarus in Frauenfeld aufsuchte und seinen Besuch 1809 in Hufelands Journal der practischen Heilkunde schilderte, erfuhr die Öffentlichkeit wieder von ihm.

Als 1812 Professor Karl Christian Wolfart im Auftrag des preußischen Staates in Frauenfeld erschien, um Mesmers System von ihm persönlich kennenzulernen und ihm die Veröffentlichung seiner Gedanken in einer großen Publikation ermöglichte, da begann für Mesmer die lange ersehnte wissenschaftliche Anerkennung und jene zweite Periode des Mesmerismus, die ihn weit überdauerte ${ }^{3}$.

${ }^{2}$ Für die freundliche Erlaubnis zur Veröffentlichung sei Herrn Dr. Schultze auch an dieser Stelle gedankt.

${ }^{3}$ An dieser Stelle sei auf die hervorragende Abhandlung von Bernhard Mrux, Franz Anton Mesmer und seine Beziehungen zur Schweiz, in Mitteilungen der Antiquarischen Gesellschaft in.Zürich 38 (1953) Heft 1 hingewiesen. 
Damals in Frauenfeld ließ Mesmer von EINSLE aber noch eine junge Frau malen, und da ihr Porträt als das Gegenstück zu dem Mesmers angelegt ist, darf es hier wohl auch nicht fehlen. Es ist ebenfalls von WURM erworben und im Besitz von Dr. Schultze. Wurms Beschriftung nennt Anna Maria Seeger geb. Holderrieth, Mesmers damalige Haushälterin und, da seine Großmutter mütterlicherseits eine Holderrieth war, wohl eine Verwandte. 